American Journal of Applied Sciences 8 (3): 271-276, 2011

ISSN 1546-9239

(C) 2010 Science Publications

\title{
Performance Appraisal-Management by Objective and Assessment Centre
}

\author{
${ }^{1}$ Kai-Ping Huang, ${ }^{2}$ Chien-Jung Huang, \\ ${ }^{3}$ Kuo-Hsiung Chen and ${ }^{4}$ Jui-Mei Yien \\ ${ }^{1}$ School of Management, University of Technology, Sydney, Australia \\ ${ }^{2}$ Department of Marketing and Distribution Management, \\ Fortune Institute of Technology, Taiwan \\ ${ }^{3}$ Department of Business Administration, Cheng Shiu University, Taiwan \\ ${ }^{4}$ Department of Leisure Management, University of Kang Ning
}

\begin{abstract}
Problem statement: Two methods for performance appraisal that are discussed in this study and they are Management By Objective (MBO) and Assessment Centre techniques. Employees are appraised for several reasons, the most important of which is to realize the best use of human resources and to plan for future needs; reward and punishment are secondary. Assessment Centre evaluation or appraisal is valuable because it allows a candidate to concentrate on the task at hand. Approach: The literature review and arguments were conducted to provide a systematic discussion of the study. Results: In Management by Objective performance appraisal, employees are obliged to deal with overcoming empirical challenges. In Assessment Centre Appraisal, the different outcomes for particular tasks can be evaluated and management can assess employees' relative proficiencies in terms of these tasks. In both forms, consistency in criteria is crucial, for purposes of comparison and standardization. Where comparisons are made with other employees, the criteria need to be parallel for employees at similar levels of responsibility. Conclusion: Differences between organizational cultures will impact on the way that assessment results are received under MBO performance appraisal as well. The outcomes that employees achieve in the tasks provided for appraisal purposes may involve different levels of risk, even within firm guidelines. In the assessment centre, the candidate is separated from colleagues. To make comparative rating assessments, effective MBO will incorporate objective criteria. At times, MBO will be useful in judging change over time for employees performing fairly routine work.
\end{abstract}

Key words: Management by objective, assessment centre, organization performance, performance appraisal, organizational culture, employees performing, human resources, organisation members

\section{INTRODUCTION}

Performance can be formal or informal. Managers and peers have beliefs or opinions concerning the relative efficiencies of organisation members. Employees may be over-valued or under-valued in terms of their output and their efficient and effective use of resources depending on how they are appraised. Appraisal takes place in organizations whether there is a formal procedure for its conduct or not. We all appraise other people. It takes place as social interaction. It should not be surprising therefore that it also forms part of our working contracts. (Clark, 2000). The key issue to performance appraisals is that they have to specify what is expected of the employee.
An appraisal system would be used to reinforce productivity and quality efforts, to develop and improve performance and to provide input into main decisions about employees. However, where formal appraisal techniques are in place and where common criteria are used, relative and quantifiable results are likely to result in fairer evaluations that are effective in terms of human resources and so allow for wise allocation of this resource and result in savings because unnecessary investment in this area is avoided. Alternately, profits may be enhanced because shortfalls are recognised, so that more human resources are recruiting that generate increased revenues. Two methods for performance appraisal that are discussed in this study are Management by Objective (MBO) and Assessment Centre techniques.

Corresponding Author: Chien-Jung Huang, Department of Marketing and Distribution Management, Fortune Institute of Technology, Taiwan 
Am. J. Applied Sci., 8 (3): 271-276, 2011

\section{MATERIALS AND METHODS}

Literature review and arguments provide a systematic discussion on two methods for performance appraisal which are management by objective and assessment centre.

Reasons for appraisal: Employees may not always perceive the objective existence of human resource practices as the organization intends (Whitener, 2001). Some members of organizations may see appraisal as threatening because they fear being penalised; alternately, they may look forward to it because they expect rewards. But performance appraisal cannot be simply connected with reward and punishment. Employees are appraised for several reasons. An organization will want to inform employees of standards to be incorporated in their work practices, or to bring about consistency between employee actions and corporate goals. Thus the appraisal is to establish levels of conformity intended to improve organizational outcomes. Appraisal will also aid in decisions and planning concerning recruitment and the potential of human resources already within the firm relative to potential for development and potential. Reward and punishment are reasons for appraisal, but they are ancillary to the benefits and costs to the firm that appraisal can reveal. Appraisal can also be used to set levels of remuneration for given levels of proficiency and as incentives for staff to strive for optimum levels of productivity. Appraisal can also be used to justify demotion or dismissal or other corrective action (Clark, 1992). An effective performance appraisal system could help the co-op in reaching organization's goals and objectives through staff development and improved communication. Not only can employee training needs could be addressed and identified, but hidden talent can be discovered as well.

MBO and assessment centre evaluation: Performance appraisal using Management by Objectives or Assessment Centre are both useful tools for developing and preparing staff for future roles within an organization and for assessing levels of proficiency in their current organizational roles. But each has drawbacks as well and optimally the two forms could be treated as complementary to each other in the work environment. However, depending on time and budgeting constraints it may be requisite on personnel management to make a decision where one is preferred to the other.

The assessment center has become widely used in organizations as a tool to select and develop leadership talent (Spychalsky et al., 1997; Krajewski et al., 2007). The popularity of the assessment center is largely due to consistent evidence of its criterion-related validity (Arthur et al., 2003).
Assessment Centre evaluation or appraisal is valuable because it allows a candidate to concentrate on the task at hand. Distractions can be minimized and real proficiency or potential can be seen in play, in regards to a particular task. The monitor is able to evaluate how particular tasks are approached and to quantify achievement levels comparatively with other candidates. Further, the monitor can come to understand any impediments that affect the individual candidate and devise strategies for overcoming them. In an empirical setting, rather than the clinical setting of the workplace, such in depth personal evaluation may not be possible.

On the other hand, assessment centres suffer the disadvantage of not reflecting the candidate's abilities or responses to the exigencies and pressures of real circumstances that occur in the workplace. In Management by Objective performance appraisal, employees are obliged to deal with overcoming empirical challenges. In most non-clinical scenarios, employees will not be able to concentrate on single tasks at any given time. This incapacity is increasingly apparent the higher up an organizational pyramid a candidate is, whether as an expert or manager. The more informed the employee is, or the more pivotal is his or her position, the more likely it is that demands will be made by other members of the organizations to help solve problems or make decisions in a number of areas, or give authority or advice concerning several matters.

Emphatic outcomes: Management by Objective will not allow monitors the opportunity to see how employees resolve or deal with every eventuality over a work period, but only to concentrate on outcomes. The way an employee arrives at these outcomes may not actually mean that resources have been used efficiently, or even as effectively as they may have been. The productivity may seem to be high or low, relative to the cost of the employee to the organisation. But it may be that the work environment is such that it is compensating for the employee's inefficiencies, or ineffectiveness, or that the employee is producing at a higher or superior rate despite difficult circumstances in the environment. Comparative evaluation is still useful as a benchmark where the workplace environment is an implicit factor in output, but such evaluation is only proximal and secondary.

Complementary methodologies: So, it is clear that both forms of evaluation are viable and useful but often that ideally neither can stand-alone. Monitors who can set up clinical settings can provide rankings to employees in regards to particular tasks and technical knowledge in regards to effectiveness and problem 
solving. Later or consequent to having a range of outcomes for employees, comparisons and contrasts can be made relative to similarities and differences in proficiencies and outcomes. An overview of this type could lead to decisions and strategic devices for improving the performance of employees relative to potential, based on deeper and broader holistic perceptions by management.

Employee and the workplace environment: Such improvement may be contingent on improving the workplace either in terms of physical or more ephemeral circumstances like morale or by providing incentives; in some cases, it may be requisite to introduce strategies or penalties to reduce shirking, which may account for the differences between results at an assessment centre and those provided through Management by Objectives. Management may find that it is cost-effective to include more stringent monitoring if there is a considerable difference in results between the two forms of assessment appraisal, or to make the prospect of increased remuneration more tangible, so that motivation is enhanced. In regards to the cost of appraisal, "A primary component of any useful or meaningful productivity improvement program is its measurement system. In the input/output analysis, the quality and quantity of human resources and their efforts are critical factors influencing productivity improvement”. (Henderson, 1980). Thus, the cost of employee appraisal is not so much a liability, as it is vital for increased productivity and the maximization of opportunities to be derived from employees.

Quantification: However, when these different forms of appraisal are not used to corroborate each other, they each must meet a number of requirements. In MBO, the results need to be quantifiable in both the long and short term (Nankervis et al., 2002). Thus there is an in-built mechanism for comparison. Where results are graphed, upward spikes in performance or uncharacteristic downturns can be seen in the context of the output and performance. The different outcomes for particular tasks can be evaluated and management can assess employee's relative proficiencies in terms of these tasks. But it can be difficult to implement MBO assessments in their ideal form because of the time frame logistics. (Nankervis et al., 2002). Staff making assessments may move, as may staff being assessed; parameters, such as technology, or contingent human resources, or the physical environment may all make long term assessment impractical and wasteful of resources.
Autonomy: Autonomy may be the one of the most fundamental psychological needs (Sheldon et al., 2001) and individual differences in autonomy orientation could in part explain why people react differently to external interventions, such as goal setting (Lee et al., 2003; Vincent et al., 2009). The employee in an MBO programme ideally has autonomy in the areas be appraised so that the efficiency or inefficiency of other workers does not impinge on the candidates performance results. Where comparisons are made with other employees, the criteria need to be parallel for employees at similar levels of responsibility. It may be, for example, that some employees' efforts do not generate results in the short term; their efforts may be based over a longer time frame. It would be inappropriate to compare outcomes for this employee against one whose output is tied to daily or hourly performance schedules.

Transparency of assessment: Within MBO, employees being assessed may need to know they are being assessed, according to (Nankervis et al., 1993). Where an employee knows that he or she is being assessed, then performance is likely to be optimised and in this way the monitor can realize the full realizable value of the employee as a human resource under ideal conditions, from the point of view of management.

Again, employees often want feedback, but they are not given it, especially at more senior levels; thus it is hard to realize the relative value of their performance compared to their peers and so cannot set in place plans for self-improvement, other than on their own cognition. For example, "At the executive level, there is often almost no regular performance feedback other than superficial praise or criticism for some crisis." (Cascio, 2002). Whether MBO or assessment centre methodology is used can depend on the position held in an organizational hierarchy. In this case, where managers cannot be monitored or appraised in any depth because senior management lacks the time, or because no other senior member of staff has the expertise to make judgments about a fellow manager, MBO is unlikely to be appropriate or feasible. Management consultants, however, can devise assessment center strategies for advising such managers and so give them direction for self-improvement.

Standardization: Finally, because management will normally have some preferred methodology for achieving outcomes and because of the need to assess employees according to standardized criteria, then a standard procedure will be requisite for achieving predetermined outcomes. (Nankervis et al, 1993). Where these standards are used however, they may 
result in lower apparent efficiency if an employee normally uses alternative methods. If the outcomes realized in the MBO programme are lower than expected, then management could be well advised to review its approach to standardized expectations. Perhaps a Chi-squared test would be valuable in comparing employees' performances against their different performances, so that significance deviations from personal normal practice can be recognized.

\section{RESULTS}

Assessment center devices for making assessments include in-basket exercises for demonstrating how well candidates' priorities work flows and Leaderless Group Discussions (LGD), (Kramar et al., 1997) which provides a monitor or assessor with an insight as to how well a candidate can think or contribute to a brainstorming scenario without superior direction. Such an exercise can indicate initiative and the candidate's ability to work in a team, which is of pre-eminent importance for a potential manager.

Business games are also used in this context where candidates make decisions based on hypothetical scenarios and have to accept the consequences of their decisions. If the candidate's decision has fortuitous consequences, he or she will be rewarded by increased productivity and profits, as well as a boost in personal kudos and opportunity for advancement in the firm, if an employee, or expansion of the firm if an entrepreneur. However, if the plan fails, because the new labor cannot or will not achieve the desired improvements in productivity, or if it demands a higher increase on its starting wage, or if it takes newly learned portable skills to another firm, then the candidate in the business game will be responsible. He or she will suffer ignominy because labor has been poorly selected. Alternately, because once the labor is trained without having been bound by a firm contract, it is too expensive to let them go and replace them, so higher wages than expected have to be paid. If the labor leaves and goes to another firm which does not have to bear the cost of training, then the candidate's firm can lose a competitive edge. The firm may fail, or the candidate in the business game may be denied further access to promotion or be dismissed.

These devices for assessment are all quite effective and provide insights, but they are based in hypotheses; the candidate does not have access to exogenous information that would affect decisions in terms of prioritizing in-trays or making decisions in business games. The devices remain games. As such, they may give insights into intelligence and the levels of risktaking behavior likely in the candidate. Whether risk averse, risk neutral or risk loving employees are desirable can depend very much on organizational culture.

Of course, differences between organizational cultures will impact on the way that assessment results are received under MBO performance appraisal as well. The outcomes that employees achieve in the tasks provided for appraisal purposes may involve different levels of risk, even within firm guidelines. The riskloving employee will advise on the upper limit and so expose the firm to a higher probability of malfeasance; the more cautious employee will recommend shares with the lower level of risk; such recommendations may expose the firm to accusations of inadequate business acumen.

In an MBO setting, the actual results of decisions can be seen, while in assessment centre appraisal they can only be extrapolated. But in each case, it can still be difficult for a monitor to ascertain whether the candidate is appraised independently of the setting for the appraisal, whether it is the assessment center laboratory or the empirical workplace in a market setting, where real business and economic factors come into play (Basu and Datta, 2010)

It can also be difficult for the firm to distinguish between individuals where their jobs are interrelated. (Campbell et al., 1998). This difficulty, however, is an important distinction between the two appraisal methods considered here. In the assessment centre, the candidate is separated from colleagues. The assessment centre is also more likely to evaluate performance using clinically testing tools such as Behaviorally Anchored Rating Scales (BARS); Behavioral Observation Scales (BOS); and Behavioral Discrimination Scales (BDS). These tools can be applied over a longer time frame, as in an MBO context, (Campbell et al.,1998) but the cost of monitoring is high, as is the level of intrusiveness on the employee undergoing appraisal. But in an assessment centre setting, the employee is ready to undergo such intrusion, while the costs of monitoring and evaluation are clearly limited within allocations. Even so, if the period over which these tools are used is limited to one or two days, short term vagaries or illness can affect the results.

MBO can be used for lower level tasks, where decision-making is not a major function of the job. Technology is an aid in this respect. Computers can be used to measure keystroke errors or incorrect decisions at an operational level, so that average levels of performance at a certain hierarchical level are extrapolated. But beyond this level, MBO can lack opportunities for truly deep employee analysis, unless considerable time is given to setting up criteria for assessment (Chegini, 2010). To make comparative rating assessments, effective $\mathrm{MBO}$ will incorporate objective criteria. For example, "BARS use more objective, behavioral standards. The standard is a 
detailed description of observable behavior, such as submits reports on time with no spelling, typing, or grammatical errors; writes clearly and succinctly" (Gordon, 1986).

\section{CONCLUSION}

Performance appraisal is clearly difficult but essential for a firm that need manage its human resources effectively in order to reduce costs and maximize profits (Al-Zhrani, 2010). The number of organizations using performance appraisals as a managerial tool necessary for facilitating the performance levels necessary to achieve the company's mission and strategies is on the increase (Carifio, 2010). Many companies are just now realizing what an effective tool a performance appraisal can be. They have begun to emphasize the correct use of performance appraisals in their organizations for the betterment of the company (Doleh and Weir, 2007).

Firms that want to maintain high morale will also ensure that their staffs feel appreciated and that their worth is fairly reckoned. Such staffs are likely to be motivated to achieve such recognition. But the firm must have devices for ensuring accurate measurement that employees have confidence in and which allow the firm to make fair judgments regarding their use and future needs of human resources. Therefore it is essential that human resource managers know when to use appropriate types of evaluation (Olugu and Wong, 2009). At times, MBO will be useful. Where a firm has to make decisions between a small number of executives, the time and costs to evaluate them will probably be justified. MBO will also be useful in judging change over time for employees performing fairly routine work. Assessment Centers, however, will be more suited to middle and senior staff who do not have peers to monitor them, or where potential is more important than everyday practice, or where there is reason to believe that significant changes can be made to current inputs from human resources. Neither MBO nor assessment centre methodologies, then, can be started categorically as superior. In some contexts, one is preferred to the other, or the two can be used in conjunction, or some other method might be optimal. Wise and reflective human resource managers will decide which method to use depending on context and circumstance.

\section{REFERENCES}

Al-Zhrani, S., 2010. Management information systems role in decision-making during crises: Case study. J. Comput. Sci., 6: 1247-1251. DOI: 10.3844/jcssp.2010.1247.1251
Arthur, W., E.A. Day, T.L. McNelly and P.S. Edens, 2003. A meta-analysis of the criterion-related validity of assessment center dimensions. Person. Psychol., 56: 125-153. DOI: 10.1111/j.17446570.2003.tb00146.x

Campbell, D.J., K.M. Campbell and H.B. Chia, 1998. Merit pay, performance appraisal, and individual motivation. An analysis and alternative. Hum. Resource Manage. J., 37: 131-144. DOI: 10.1002/(SICI)1099050X(199822)37:2<131::AID-HRM4>3.0.CO;2-X

Carifio, J., 2010. Development and validation of a measure of relational leadership: Implications for leadership theory and policies. Current Res. Psychol., 1: 16-28. DOI: 10.3844/crpsp.2010.16.28

Cascio, W.F., 2002. Managing Human Resource: Productivity, Quality of Work Life, Profits. 6th Edn., McGraw-Hill, Sydney, ISBN-10: 0072317167, pp: 703.

Chegini, M.G., 2010. The relationship between organizational culture and staff productivity public organizations. J. Soc. Sci., 6: 127-129. DOI: 10.3844/jssp.2010.127.129

Clark, R., 2000. Australian Human Resource Management: Framework and Practice. 3rd Edn., McGraw-Hill, Sydney, ISBN-10: 0074707582, pp: 534.

Doleh, J. and D. Weir, 2007. Dimensions of performance appraisal systems in Jordanian private and public organizations. Int. J. Hum. Resource Manage., $\quad$ 18: $\quad 75-84 . \quad$ DOI: 10.1080/09585190601068334

Gordon, J.R., 1986. Human Resource Management: A Practical Approach. 1st Edn., Allyn and Bacon, Sydney, ISBN-10: 0205086047, pp: 771.

Henderson, R., 1980. Performance Appraisal: Theory to Practice. 1st Edn., A Prentice-Hall Company, Virginia, ISBN-10: 0835954986, pp: 310.

Krajewski, H., R. Goffin, M. Rothstein and N. Johnston, 2007. Is Personality related to assessment center performance? That depends on how old you are. J. Bus. Psychol., 22: 21-33. DOI: 10.1007/s10869007-9043-z

Kramar, R., P. McGraw and R.S. Schuler, 1997. Human Resource Management in Australia. 3rd Edn., Longman Australia, Australia, ISBN-10: 0582811139, pp: 617.

Lee, F.K., K.M. Sheldon and D.B. Turban, 2003. Personality and the goal-striving process: The influence of achievement goal patterns, goal level, and mental focus on performance and enjoyment. J. Applied Psychol., 88: 256-265. DOI: 10.1037/0021-9010.88.2.256 
Nankervis, A.R., R.L. Compton and T.E. McCarthy, 2002. Strategic Human Resource Management. 4th Edn., Thomas Nelson, South Melbourne, ISBN: 0170104672, pp: 690.

Olugu, E.U. and K.Y. Wong, 2009. Supply chain performance evaluation: trends and challenges. Am. J. Eng. Applied Sci., 2: 202-211. DOI: 10.3844/ajeassp.2009.202.211

Sheldon, K.M., A.J. Elliot, Y. Kim and T. Kasser, 2001. What is satisfying about satisfying events? Testing 10 candidate psychological needs. J. Person. Soc. Psychol., 80: 325-339. PMID: 11220449

Basu, S. and S.K. Datta, 2010. The success story of voluntary retirement scheme in national carbon company: a unit of Eveready Industries India Ltd. Am. J. Econ. Bus. Admin., 2: 157-159. DOI: 10.3844/ajebasp.2010.157.159
Spychalsky, A.C., M.A. Quinones, B.B. Gaugler and K. Pohley, 1997. A survey of assessment center practices in organizations in the United States. Person. Psychol., 50: 71-90. DOI: 10.1111/j.17446570.1997.tb00901.x

Vincent, R., S. Salek, C. Aubé and E.M. Morin, 2009. Distributive justice, procedural justice, and psychological distress: The moderating effect of coworker support and work autonomy. J. Occup. Health Psychol., 14: 305-317. DOI: 10.1037/a0015747

Whitener, E.M., 2001. Do "high commitment" human resource practices affect employee commitment? A cross-level analysis using hierarchical linear modeling. J. Manage., 27: 515-535. DOI: 10.1177/014920630102700502 